\title{
Correction to: Electrophysiological and behavioral responses Dendroctonus frontalis and $D$. terebrans (Coleoptera: Curculionidae) to resin odors of host pines (Pinus spp.)
}

Holly L. Munro ${ }^{1}$ (I) Kamal J. K. Gandhi ${ }^{1}$ - Brittany F. Barnes ${ }^{1}$ - Cristian R. Montes ${ }^{1}$. John T. Nowak ${ }^{3}$. William P. Shepherd ${ }^{2} \cdot$ Caterina Villari $^{1} \cdot$ Brian T. Sullivan $^{2}$

Published online: 14 October 2020

(c) Springer Nature Switzerland AG 2020

Correction to: Chemoecology (2020) 30:215-231

https://doi.org/10.1007/s00049-020-00311-7

In Table 2 (Page 220) the units given for release rates of the endo- and exo-brevicomin flexlures should be $\mathrm{mg}$ rather than $\mu \mathrm{g}$ (i.e., both had a release rate of $0.12 \mathrm{mg} /$ day).

The original article can be found online at https://doi.org/10.1007/ s00049-020-00311-7.

Holly L. Munro

hmunro@uga.edu

1 D.B. Warnell School of Forestry and Natural Resources, University of Georgia, 180 East Green Street, Athens, GA 30602, USA

2 USDA Forest Service, Southern Research Station, 2500 Shreveport Highway, Pineville, LA 71360, USA

3 USDA Forest Service, Forest Health Protection, 200 W.T. Weaver Blvd, Asheville, NC 28804, USA 